\title{
Theory Research and Practice of Structure Safety Measures and Deformation Prediction in Goaf
}

\author{
Peng Deng ${ }^{1, a}$,Lei Tai, ${ }^{1, ~ b}$,Huiling Wang ${ }^{1, \mathrm{c}}$,Qibiao Zhang $^{2, \mathrm{~d}}$ \\ ${ }^{1}$ College of Civil Engineering, Shandong University of Science and Technology \\ Qingdao, Shandong 266590, China \\ ${ }^{2}$ Jining Dongfang Construction Engineering Supervision Co., Ltd, Jining, 272000, China

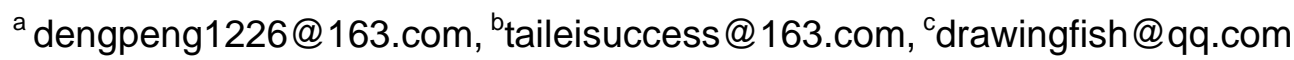 \\ d1161218295@qq.com
}

Keywords: Goaf; Ground Deformation; Pressure Releasing groove

\begin{abstract}
Recently, coal mining in Jining has extended to the crowded cities and villages, bringing out the deformation of the rock in these areas, which leads to the damage of the civil and industrial buildings. Therefore, the ground surface deformation and the damage characteristics of the buildings have been studied, and appropriate safety measures have been taken according to different damage characteristics to reduce or even to avoid the damage of the buildings. The effect of different mining schemes on the ground has been analyzed, and the effects on important buildings have been studied. Safety measures have been taken on the space truss, oil tanks and pipelines of gas station and tensile stress of soil have been released by pressure releasing groove around the station. Some conclusions have reference significance for other relevant projects.
\end{abstract}

\section{Introduction}

Deformations of goaf areas include surfaces subsidence, horizontal displacement and curvature. But whole deformation of goaf is basin shaped [1], and the movement of ground in the center of basin is simple vertical deformation, so it has little effect on safety of the building [2]. But the buildings at the edge of the basin incline seriously, and underground pipelines bend due to tensile stress in layer. Therefore, it is necessary to take reinforcement and maintenance measures [3], which traditionally include increasing section dimension of structure, setting deformation joint, ring beam and constructional column[4], while automatic adjustment joints according to the surface deformations and the release of tensile stress in soil are adopted currently, which is to set pressure releasing groove[5].

Two kinds of mining schemes are put forward in this paper according to the distribution features of coalfield, the ground surface deformation is forecasted and the mining risk and profit are also analyzed, which bring out the conclusion that one scheme has good profit but some buildings and industrial facilities have certain risk, while another one with the less profit is denied. Therefore, a special pre-reinforcement scheme is put forward according to the deformation characteristics of ground and structure features, and a soil stress relief scheme is used for pipelines, which make sure the safety of the gas station, and some conclusions have reference significance for other relevant projects both at home and abroad.

\section{Mining Scheme and Surface Deformation Forecasting}

Jining coalfield is located in the southern region of Zaozhuang, the formation has the Quaternary, the Upper Jurassic, the Permian, the Carboniferous and the Ordovician, the main coal-bearing formations are Shanxi group of Lower Permian and Taiyuan group of Upper Carboniferous. The average thickness is about $270 \mathrm{~m}$, including a total of 19 coal-bearing formations, and the coal-bearing coefficient is $3.3 \%$. Shanxi group is the main coal-bearing formation of this field, and the average thickness is $118.8 \mathrm{~m}$, including $2 \sim 3$ coal-bearing formations, and the thickness of each layer is big and the structure is simple. 
According to the random medium theory, the subsidence basin caused by mining is normally distributed, which consists with the distribution of probability density. Therefore, the subsidence section equation can be expressed as integral formula of the probability density function, the surface unit of subsidence basin expression is:

$$
w_{e}(x)=\frac{1}{r} e^{-\pi \frac{x^{2}}{r^{2}}}
$$

In the type: $\mathrm{R}$ is the main influence radius, which is related to the mining depth and the main influencing angle.

The expression of surface horizontal movement can be deduced by the upper expression:

$$
u_{e}(x)=-\frac{2 \pi \mathrm{B} x}{r^{3}} e^{-\pi \frac{x^{2}}{r^{2}}}
$$

In the type: B is constant.

Scheme 1 is to stop mining under the area of gas station, while scheme 2 is to recover the region, and according to the observation of ground deformation and building of gas station, the ground subsidence is $500 \mathrm{~mm}$, the maximum slope deformation is $4 \mathrm{~mm} / \mathrm{m}$, the maximum curvature deformation is $0.06 \mathrm{~mm} / \mathrm{m} 2$ and the maximum horizontal deformation is $3 \mathrm{~mm} / \mathrm{m}$. The buildings of gas station have been in the critical deformation range. The relationship of band mining and gas station is shown in Fig.1. Though stopping mining in this region is safer, it has little profit. Scheme 2 is to recover the region, and the surface deformation of scheme 2 is bigger than scheme 1 , as shown in table 1.

\begin{tabular}{|c|c|c|c|c|c|c|c|c|c|}
\hline \multirow[b]{2}{*}{$\begin{array}{l}\text { Mining } \\
\text { scheme }\end{array}$} & \multirow[b]{2}{*}{$\begin{array}{l}\text { Sinking } \\
\text { addition } \\
(\mathrm{mm})\end{array}$} & \multicolumn{4}{|c|}{ Tendency addition } & \multicolumn{4}{|c|}{ Strike addition } \\
\hline & & $\begin{array}{c}\text { Slope } \\
(\mathrm{mm} / \mathrm{m})\end{array}$ & $\begin{array}{l}\text { Curvature } \\
\left(\mathrm{mm} / \mathrm{m}^{2}\right)\end{array}$ & $\begin{array}{l}\text { Horizontal } \\
\text { deformation } \\
(\mathrm{mm} / \mathrm{m})\end{array}$ & $\begin{array}{l}\text { Horizontal } \\
\text { movement } \\
(\mathrm{mm})\end{array}$ & $\begin{array}{c}\text { Slope } \\
(\mathrm{mm} / \mathrm{m})\end{array}$ & $\begin{array}{l}\text { Curvature } \\
\left(\mathrm{mm} / \mathrm{m}^{2}\right)\end{array}$ & $\begin{array}{l}\text { Horizontal } \\
\text { deformation } \\
(\mathrm{mm} / \mathrm{m})\end{array}$ & $\begin{array}{l}\text { Horizontal } \\
\text { movement } \\
\quad(\mathrm{mm})\end{array}$ \\
\hline 1 & $0 \sim 30$ & $0 \sim 0.05$ & $0 \sim 0.005$ & 0.00 & $-30 \sim 0$ & $0 \sim 1$ & $0 \sim 0.03$ & $0 \sim 1.8$ & $0 \sim 90$ \\
\hline 2 & $0 \sim 50$ & $-0.5 \sim 0$ & $0 \sim 0.008$ & 0.05 & $-48 \sim 0$ & $0 \sim 2.2$ & $0 \sim 0.042$ & $0 \sim 3.2$ & $0 \sim 180$ \\
\hline
\end{tabular}

Table1 The addition of surface movement and deformation

Through the analysis of the surface deformation, it can be obtained that the pillar top relative maximum horizontal displacement is $105 \mathrm{~mm}$ and the relative maximum vertical displacement is $204 \mathrm{~mm}$. The overall surface deformation leans to southwest, so as the space truss. Because the structure has been built for a long time and the construction enterprise does not have good relevant technical and management ability, so the space truss exists big danger. According to the whole surface deformation tendency, it can be got that the tensile stress leads to the excessive deformation of the pipeline and even fracture, which causes the leakage of oil and gas, bringing out security disaster.

\section{Reinforcement scheme of Space Truss}

The space truss uses four-point supporting with reinforced concrete columns, and the planar projection is rectangle. The structure has total of $7 \times 10$ grids, and the dimension of each grid is $2.4 \mathrm{~m} \times 2.4 \mathrm{~m}$. The structure is analyzed by SAP2000, the rotation of each column base and the vertical displacements of columns are considered in the analysis model, the maximum stress is analyzed here according to "Load code for the design of building structures”(GB50009-2012) and “Technical specification for space frame structures”(JGJ7-2010).Fi rst of all, the structure are analyzed according to the current deformation parameters, the maximum rotation of column base is $0.02^{\circ}$, and the maximum vertical displacement difference is $45 \mathrm{~mm}$, the bottom chord stress change is small with the maximum of $20 \mathrm{Mpa}$, while the top chord and web member change a lot which increases $80 \mathrm{Mpa}$, so the safety of the structure has been influenced seriously. The ground deformation is 2 times of current stage according to the analysis of scheme 2 , which leads to the instability of some web members. In view of the instability of the ground deformation, more members will lose bearing ability and even the whole structure collapse, so it is essential to reinforce the space truss. 


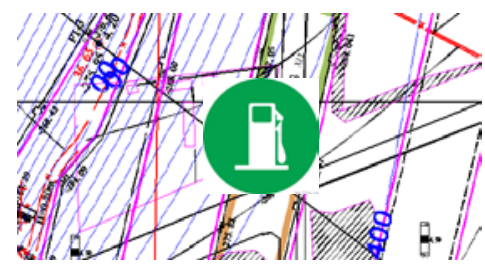

Fig.1 Relationship of the band mining and gas station

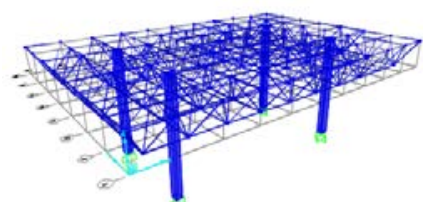

Fig.2 Analysis model of space truss

The methods of structure reinforcement usually include increasing the structural strength and stiffness, such as enlarging the section size or reinforcing the structure members with steel or carbon fiber. It is ideal to use steel columns instead of reinforced concrete columns, but this method is forbidden because of the 15 days construction duration, which means that the gas station will shutdown for half a month. A new scheme with low effect on gas station is put forward, though it is not the most economical according to construction cost. Firstly, 8 anchor bolts are set around the concrete columns, and the area around the bolts is concreted. Secondly, $4 \mathrm{H}$-shaped columns are connected with anchor bolts, as shown in Fig.3 (a), and the 4 columns work together through members. Reasonable clearance is left between new and original structures, as shown in Fig.3 (b). The sketch of steel and original structures is shown in Fig.3 (c). Finally, the base of space truss is put on the top of steel structure after the elimination of partial concrete column. Each column is dealt with the same process above. During the whole construction period, the gas station works normally. The reinforcement construction of one column is shown in Fig.4 (a).In addition, it is convenient to adjust the nuts and washes to keep the deformation and stress of structure in a regulated limit.

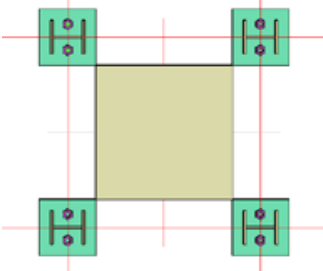

(a)Anchor bolts, $\mathrm{H}$-shaped columns and concrete columns

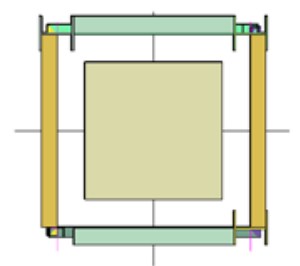

(b)The clearance between the steel and original structures

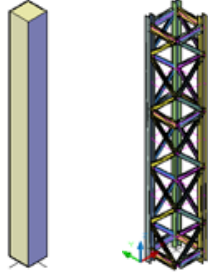

(c)The sketch of the steel and concrete columns

Fig.3 The rigid column pre-reinforcement setting

\section{Safety Schemes of Oil Tanks and Pipelines}

The ground surface horizontal deformation leads to the internal tensile stress of the gas station oil tanks and pipelines, which will lead to the crack and fuel leak. Therefore, it is necessary to take pressure relief measures, which is to excavate pressure releasing groove to decrease the tensile stress in soil. It is necessary to locate the pressure releasing groove at the external side of the building, and the depth of groove should be greater than base depth and enough horizontal distance should be kept from the base. The site construction is shown in Fig.4(b).

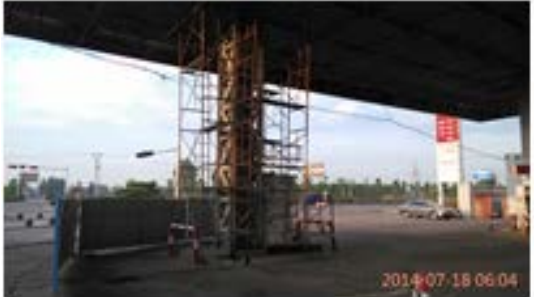

(a) Reinforcement construction

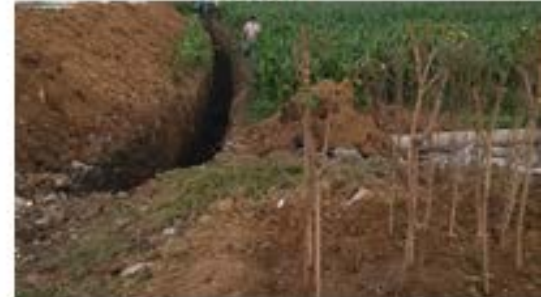

(b) The excavation of pressure releasing groove Fig.4 Structure reinforcement and pressure releasing slot excavation

\section{Conclusion}

The project has lasted for half a year, and surface deformation has been in accordance with analysis, obvious crack and deformation have appeared in the structure around mining area, According to the goaf surface subsidence and the characteristics of gas station, the gas station facilities have been reinforced and 
rectificated, and ideal effect has been got, which has ensured the safe use of gas station and facilities. The grid structure shall propose the limit steel quantity per unit area according to the similar project, the grids 1-2 near the bearing should be strictly restricted the stress, which is limited to take $50 \%$ of the steel strength design value to reserve a certain safety degree in order to meet the need of bearing displacement load effect. The gas station should be monitored to control deformations affected by coal mining in time, in order to provide information and opportunity for further rectification.

\section{References}

[1] WU Chongfu, ZHANG Ning. Force Analysis of Frame Structure under Interaction of Deformation and Earthquake in Mined-out Area.Journal of Yanshan University, 2010,34(6):556-360.

[2] HUANG Leting, CUI Jixian. Mining Subsidence Damage and Resisting Mining Deformation Building Technology Practice.The Sixth National Conference on Mining Corpu:584-586.

[3] ZHENG Yuying, XIA Junwu, et al. Study on Active Anti-deformational Pedestal with Frame Structure in Mining Area and Its Mechanical Performance.Journal of Shandong University of Science and Technology, 2012,31(1):62-66.

[4] QI Yongchuan. Building Reinforcement and Maintenance in Coal Mining Subsidence Area.China High Technology Enterprises, 2010(28):84-85.

[5] DUAN Jingmin, QIAN Yongjiu. Resistant Deformation Residential Building System in Goaf and its Reinforcement Technique. Coal Engineering, 2008(8):44-46.

[6] ZHU Chuanli, CHANG Hongfei. Study on Anti-deformation Design Buildings in Mining Area.Journal of Xuzhou Construction Vocational and Technical College, 2006,6 (2):9-11.

[7] DENG Kazhong, GUO Guangli,TAN Zhixiang,et al.Analysis of movement and deformation characteristics of buildings above mining subsidence areas[J].Journal of China University of Mining and Technology, 2001,30(4):354-358.

[8] XIA Junwu, WANG Shouxiang, WANG Kuanru,et al.Numerical simulation of anti-deformation ability of the steel portal frame over abandoned mine goaf[J].Building Structure, 2004(5):13-15. 